\title{
2D Silicon-Germanium Layered Materials as Anodes for Li-ion Batteries
}

Xi CHEN (orcid.org/0000-0001-8793-1809), Laura C. LOAIZA (orcid.org/0000-0002-3164-4509), Laure MONCONDUIT (orcid.org/0000-0003-3698-856X), and Vincent SEZNEC (orcid.org/0000-0001-52335943)*

a Laboratoire de Réactivité et Chimie des Solides (CNRS UMR 7314), Université de Picardie Jules Verne, 33 Rue Saint Leu, 80039 Amiens Cedex, France.

${ }^{b}$ Réseau sur le Stockage Electrochimique de l'Energie (RS2E), CNRS FR3459, 33 Rue Saint Leu, 80039 Amiens, Cedex, France

* Corresponding author.

E-mail: vincent.seznec@u-picardie.fr (Vincent Seznec)

xi.chen@u-picardie.fr (Xi Chen)

loaiza@chalmers.se (Laura C. Loaiza)

laure.monconduit@umontpellier.fr (Laure Monconduit)

Keywords: Layered materials, Siloxene, Siligane, Germanane, Anode, Lithium-ion battery.

(Fig. S1-a) XRD pattern of $\mathrm{CaSi}_{2}$

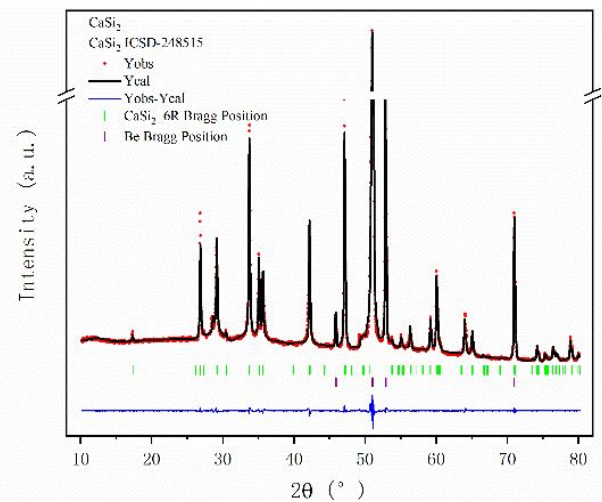

\begin{tabular}{cccc}
\hline & $\mathrm{a}($ Unit: $\AA$ ) & $\mathrm{b}($ Unit: $\AA)$ & $\mathrm{c}($ Unit: $\AA)$ \\
\hline $\mathrm{CaSi}_{2-} 6 \mathrm{R}(\mathrm{R}-3 \mathrm{~m})$ & 3.8550 & 3.8550 & 30.6778 \\
Proportion: $100 \%$ & $(0.00021)$ & $(0.00021)$ & $(0.00221)$ \\
\hline
\end{tabular}

\begin{tabular}{cc}
\hline $\mathrm{Rp}$ & Global user-weigthed Chi2 (Bragg contrib.) \\
\hline 22.9 & 71.5 \\
\hline
\end{tabular}


(Fig. S1-b) XRD pattern of $\mathrm{Ca}\left(\mathrm{Si}_{0.9} \mathbf{G e}_{0.1}\right)_{2}$

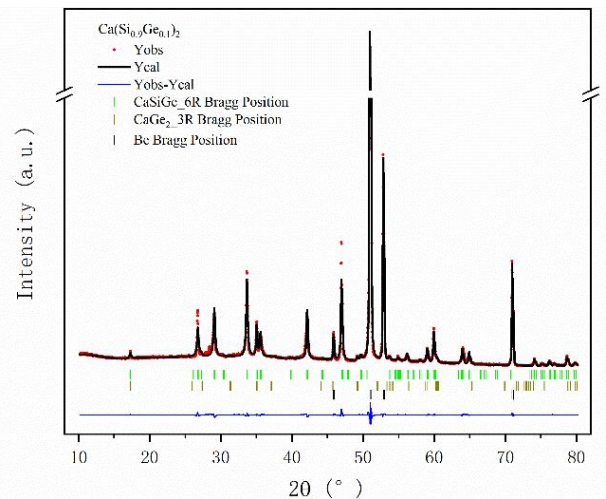

\begin{tabular}{cccc}
\hline & $\mathrm{a}$ (Unit: $\AA)$ & $\mathrm{b}($ Unit: $\AA)$ & $\mathrm{c}($ Unit: $\AA)$ \\
\hline CaSiGe_6R (R -3 m) & 3.8676 & 3.8676 & 30.6901 \\
Proportion: $94.09 \%$ & $(0.00013)$ & $(0.00013)$ & $(0.00430)$ \\
& & & 10.2475 \\
CaGe 2 3R (P 63 m c) & 3.9724 & 3.9724 & $(0.00303)$ \\
Proportion: $5.91 \%$ & $(0.00054)$ & $(0.00054)$ & \\
\hline
\end{tabular}

\begin{tabular}{cc}
\hline $\mathrm{Rp}$ & Global user-weigthed Chi2 (Bragg contrib.) \\
\hline 14.8 & 29.3 \\
\hline
\end{tabular}

(Fig. S1-c) XRD pattern of $\mathrm{Ca}\left(\mathrm{Si}_{0.5} \mathrm{Ge}_{0.5}\right)_{2}$

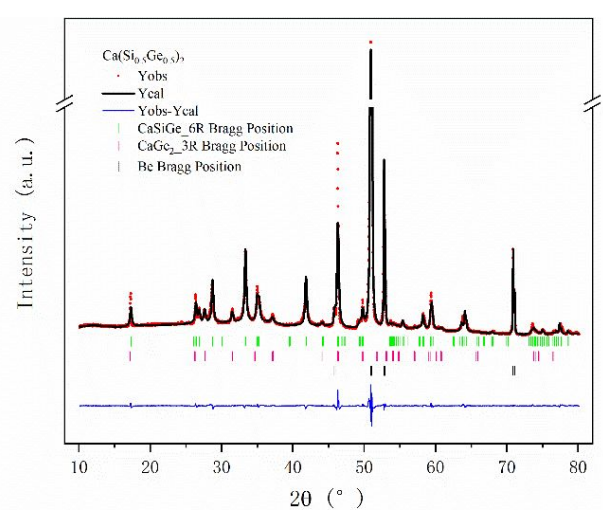

\begin{tabular}{cccc}
\hline & $\mathrm{a}($ Unit: $\AA)$ & $\mathrm{b}($ Unit: $\AA)$ & $\mathrm{c}($ Unit: $\AA)$ \\
\hline $\mathrm{Ca}\left(\mathrm{Si}_{0.5} \mathrm{Ge}_{0.5}\right)_{2-} 6 \mathrm{R}(\mathrm{R}-3 \mathrm{~m})$ & 3.9137 & 3.9137 & 30.6744 \\
Proportion: 65.63 \% & $(0.00026)$ & $(0.00026)$ & $(0.00568)$ \\
$\mathrm{CaGe}_{2-}$ 3R $(\mathrm{P} 63 \mathrm{~m} \mathrm{c})$ & 3.9134 & 3.9134 & 10.3804 \\
Proportion: $34.37 \%$ & $(0.00009)$ & $(0.00009)$ & $(0.00043)$ \\
\hline $\mathrm{Rp}$ & Global user-weigthed Chi2 (Bragg contrib.) \\
\hline 11.1 & \multicolumn{3}{c}{17.6} \\
\hline
\end{tabular}




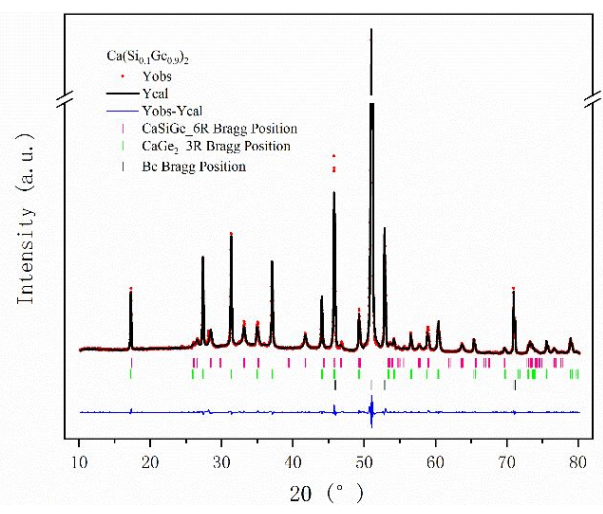

\begin{tabular}{cccc}
\hline & $\mathrm{a}($ Unit: $\AA)$ & $\mathrm{b}($ Unit: $\AA)$ & $\mathrm{c}($ Unit: $\AA)$ \\
\hline CaSiGe_6R (R -3 m) & 3.9639 & 3.9639 & 30.6509 \\
Proportion: $27.41 \%$ & $(0.00055)$ & $(0.00055)$ & $(0.00611)$ \\
CaGe_2 $3 \mathrm{R}$ (P 63 m c) & 3.9620 & 3.9620 & 10.2618 \\
Proportion: $72.59 \%$ & $(0.00008)$ & $(0.00008)$ & $(0.00091)$ \\
\hline
\end{tabular}

\begin{tabular}{cc}
\hline $\mathrm{Rp}$ & Global user-weigthed Chi2 (Bragg contrib.) \\
\hline 12.7 & 26.3 \\
\hline
\end{tabular}

(Fig. S1-e) XRD pattern of $\mathrm{CaGe}_{2}$

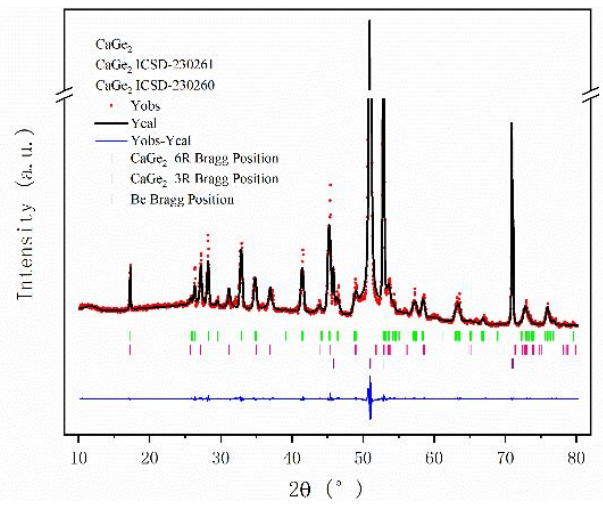

\begin{tabular}{cccc}
\hline & $\mathrm{a}($ Unit: $\AA)$ & $\mathrm{b}($ Unit: $\AA)$ & $\mathrm{c}($ Unit: $\AA)$ \\
\hline $\mathrm{CaGe}_{2}$ 6R (R -3 m) & 4.0075 & 4.0075 & 30.8291 \\
Proportion: $71.47 \%$ & $(0.00047)$ & $(0.00047)$ & $(0.00994)$ \\
& & & \\
$\mathrm{CaGe}_{2}$ 3R (P 63 m c) & 3.9978 & 3.9978 & 10.2670 \\
Proportion: $28.53 \%$ & $(0.00054)$ & $(0.00054)$ & $(0.00521)$ \\
\hline
\end{tabular}

\begin{tabular}{cc}
\hline $\mathrm{Rp}$ & Global user-weigthed Chi2 (Bragg contrib.) \\
\hline 12.4 & 17.9 \\
\hline
\end{tabular}

Fig. S1. Le Bail refinement for (a) $\mathrm{CaSi}_{2}$, (b) $\mathrm{Ca}\left(\mathrm{Si}_{0.9} \mathrm{Ge}_{0.1}\right)_{2}$, (c) $\mathrm{Ca}\left(\mathrm{Si}_{0.5} \mathrm{Ge}_{0.5}\right)_{2}$, (d) $\mathrm{Ca}\left(\mathrm{Si}_{0.1} \mathrm{Ge}_{0.9}\right)_{2}$, (e) $\mathrm{CaGe}_{2}$ XRD pattern. 

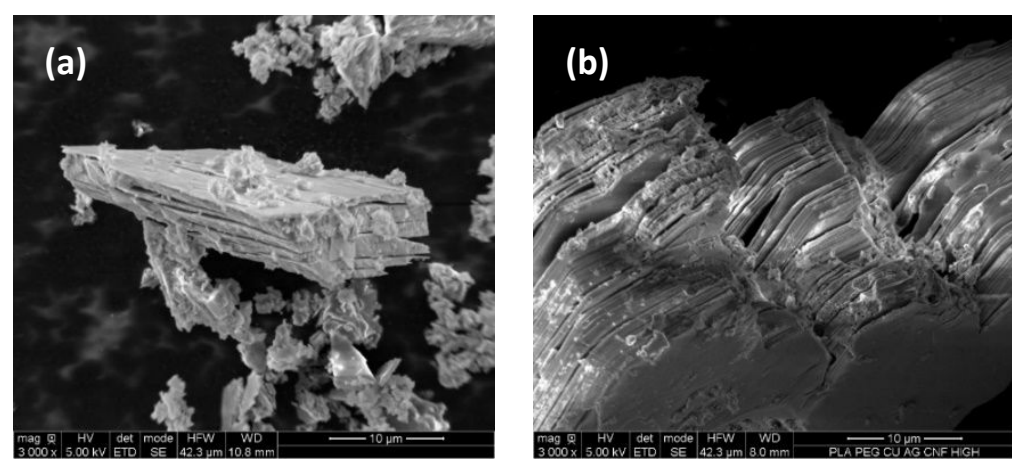

Fig. S2. SEM images of (a) siloxene and (b) germanane. 

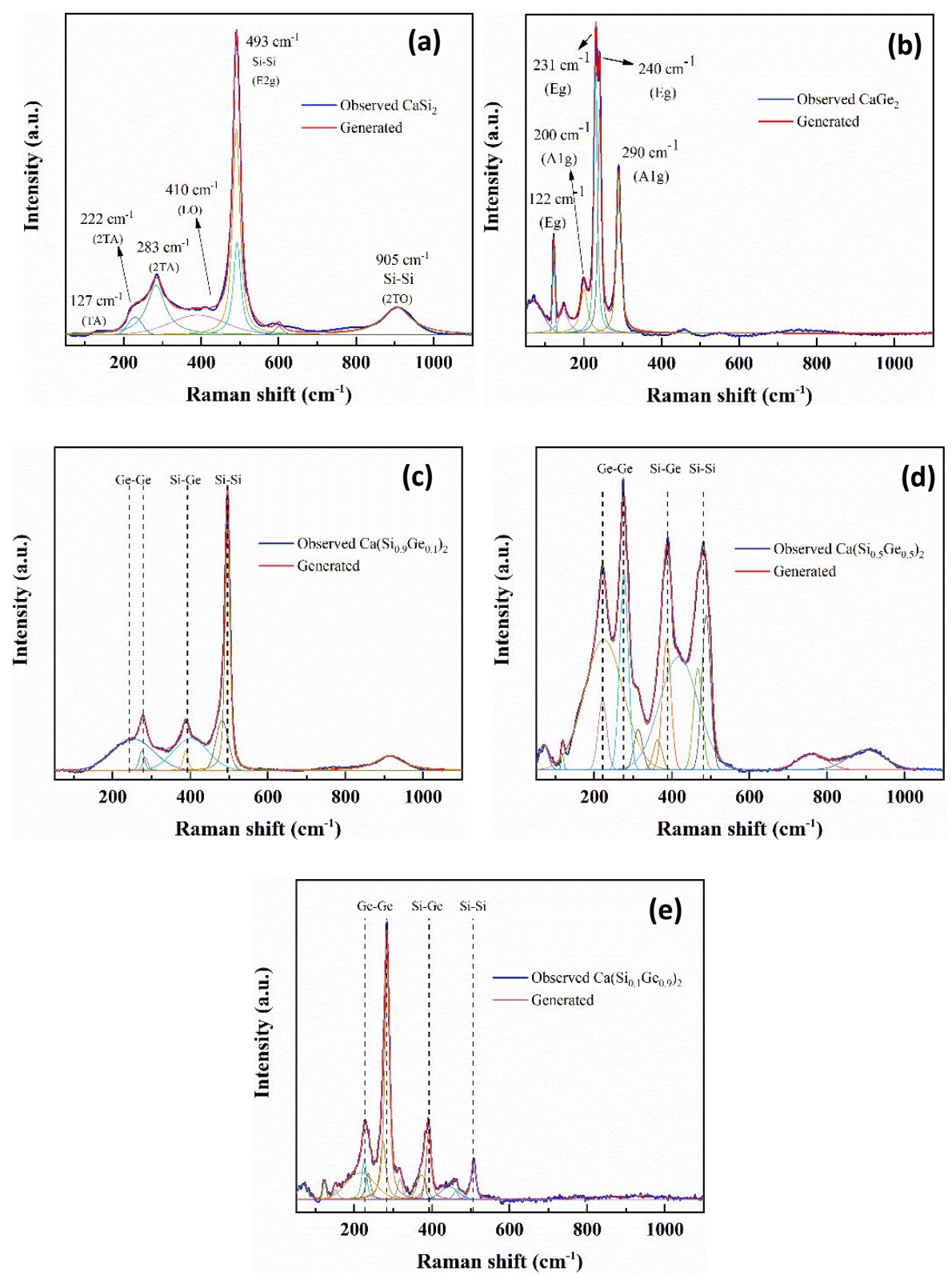

Fig. S3. (a) The Raman spectroscopy deconvolution of (a) $\mathrm{CaSi}_{2}$, (b) $\mathrm{CaGe}_{2}$, (c) $\mathrm{Ca}\left(\mathrm{Si}_{0.9} \mathrm{Ge}_{0.1}\right)_{2}$, (d) $\mathrm{Ca}\left(\mathrm{Si}_{0.5} \mathrm{Ge}_{0.5}\right)_{2}$, and (e) $\mathrm{Ca}\left(\mathrm{Si}_{0.1} \mathrm{Ge}_{0.9}\right)_{2}$. 

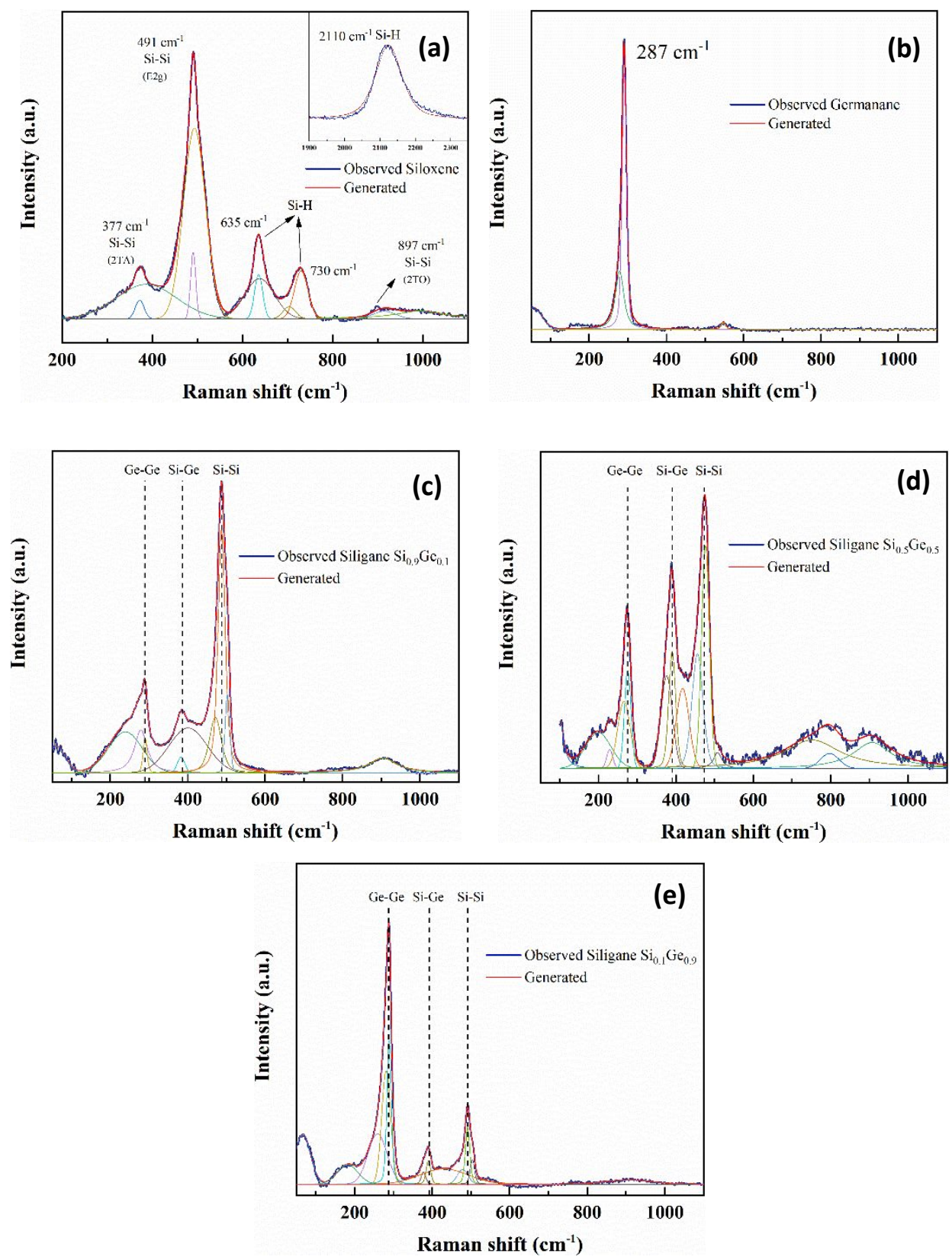

Fig. S4. (a) The Raman spectroscopy deconvolution of (a) siloxene, (b) germanane, (c) siligane_ $\mathrm{Si}_{0.9} \mathrm{Ge}_{0.1}$, (d) siligane_Si $\mathrm{Si}_{0.5} \mathrm{Ge}_{0.5}$, and (e) siligane_ $\mathrm{Si}_{0.1} \mathrm{Ge}_{0.9}$.

The Raman spectrum of 6R-CaSi 2 (Fig. S3-a in $\mathrm{SI}$ ) is shown. There is a significant peak at $493 \mathrm{~cm}^{-1}$, and some relatively weak peaks at 127, 222, 283, 410, and $905 \mathrm{~cm}^{-1}$. Based on literature reports, they are ascribed to the vibration of $\mathrm{Si}-\mathrm{Si}$ in the plane, first-order transversal optical phonons (TO) of 2D silicon-based materials appear at around 500 $\mathrm{cm}^{-1}$ (E2g symmetry). Compared with bulk silicon $\left(520 \mathrm{~cm}^{-1}\right)$, its vibration frequency shifts to a lower position. The peaks at $127,222,283$, and $410 \mathrm{~cm}^{-1}$ correspond to the combination of transverse acoustic phonons (TA) and longitudinal optical phonons (LO). The small broad peak at $905 \mathrm{~cm}^{-1}$ indicates the existence of second-order Raman 
scattering. Following, the Raman spectrum of siloxene (Fig. S4-a in $\mathrm{SI}$ ) shows a main peak at $491 \mathrm{~cm}^{-1}$, and some weaker peaks at 377, 635, 730, 897, and $2110 \mathrm{~cm}^{-1}$. The Raman mode at $491 \mathrm{~cm}^{-1}$ is attributed to the E2g vibration, while the peaks at 377 and $897 \mathrm{~cm}^{-1}$ are derived from the 2TA and 2TO of the Si-Si bond in the Si planes, respectively. The peaks at 635,730 and $2110 \mathrm{~cm}^{-1}$ correspond to the $\mathrm{Si}-\mathrm{H}$ vibration after Ca removal. ${ }^{1}$ The Raman spectrum of $\mathrm{CaGe}_{2}$ (Fig. S3-b in SI) with layered hexagonal structure has two A1g modes at 200 and $290 \mathrm{~cm}^{-1}$, corresponding to the out-of-plane lattice vibration. There are three Eg modes at 122, 231 and $240 \mathrm{~cm}^{-1}$, corresponding to the in-plane lattice vibration. Subsequently, the Raman spectrum of germanane (Fig. S4-b in SI) shows a change relative to $\mathrm{CaGe}_{2}$, and it has only one peak at $290 \mathrm{~cm}^{-1}$, which is due to the in-plane E2 mode from Ge-Ge bond. ${ }^{2}$

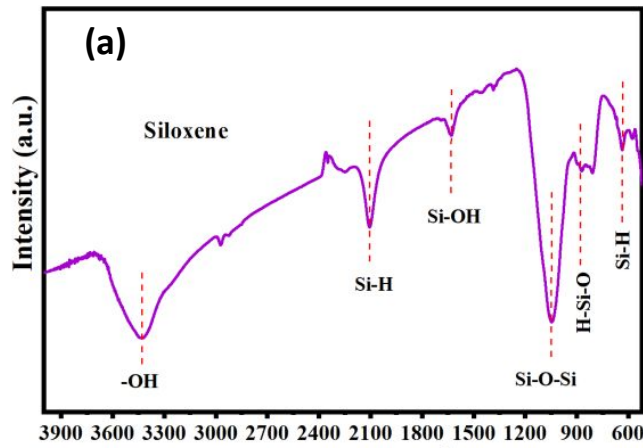
Wavenumber $\left(\mathrm{cm}^{-1}\right)$

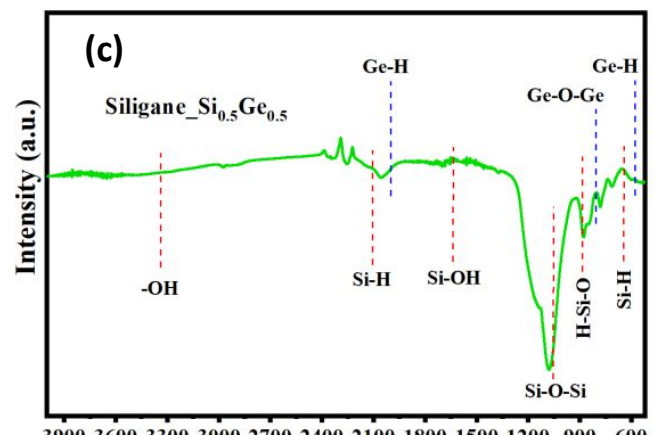

3900360033003000270024002100180015001200900600 Wavenumber $\left(\mathrm{cm}^{-1}\right)$

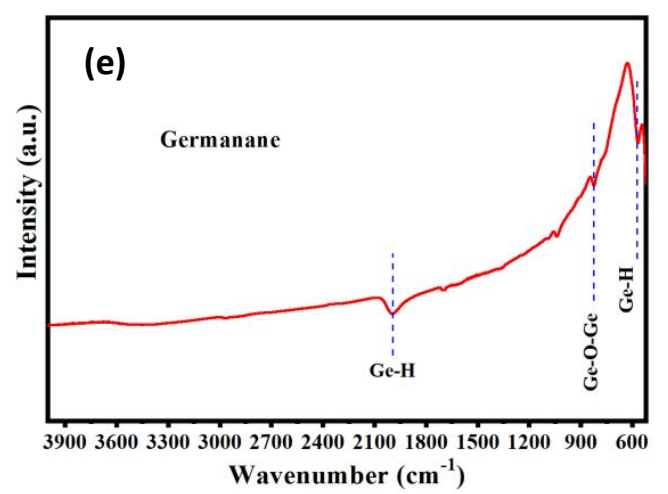

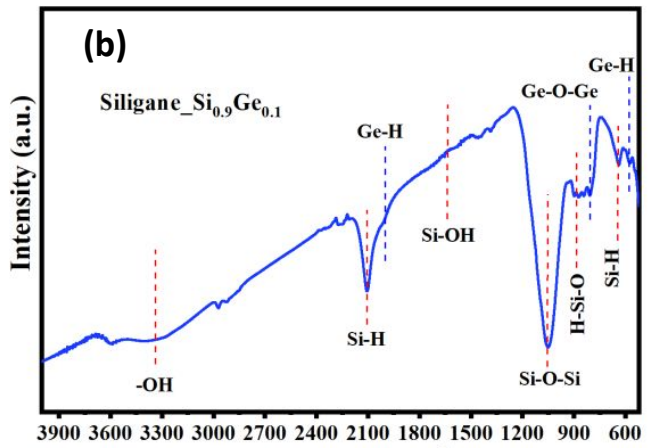
Wavenumber $\left(\mathrm{cm}^{-1}\right)$

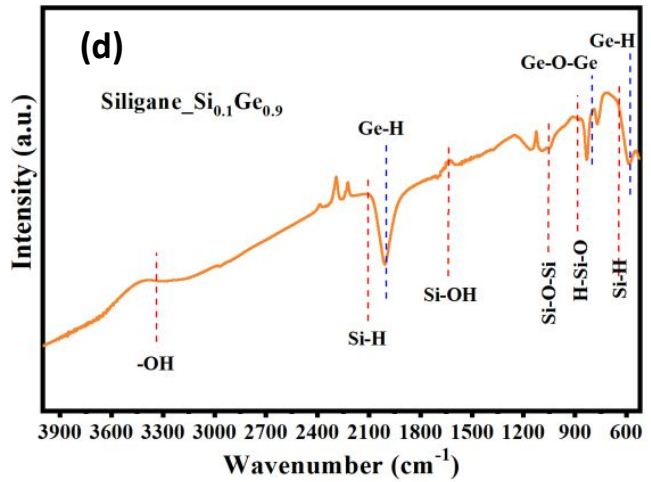

Fig. S5. The infrared spectra for (a) siloxane, (b) siligane_ $\mathrm{Si}_{0.9} \mathrm{Ge}_{0.1}$, (c) siligane_Si $\mathrm{Si}_{0.5} \mathrm{Ge}_{0.5}$, (d) siligane_Si $\mathrm{Si}_{0.1} \mathrm{Ge}_{0.9}$ and (e) germanane. 
Table S1. Assignment of infrared modes in siloxene.

\begin{tabular}{cc}
\hline$\omega\left(\mathrm{cm}^{-1}\right)$ & Assignment \\
\hline 638 & Si-H bending \\
809 & Si-O-Si symmetric stretching \\
$875 / 895$ & Si-OH/H-Si-O \\
1047 & Si-O-Si asymmetric stretching \\
1630 & $-\mathrm{OH}$ bending \\
2109 & $\mathrm{Si}-\mathrm{H}$ stretching \\
2250 & $\mathrm{H}-\mathrm{SiO}$ stretching \\
$3200-3400$ & $\mathrm{Si}-\mathrm{OH}$ bonded \\
3615 & $-\mathrm{OH}$ free \\
\hline
\end{tabular}

The siloxene (Fig. S5-a in SI) shows multiple vibration bands.

The characteristic peaks at 638,1047 , and $1630 \mathrm{~cm}^{-1}$ correspond to the vibrations of $\mathrm{Si}-\mathrm{H}, \mathrm{Si}-\mathrm{O}-\mathrm{Si}$, and $\mathrm{Si}-\mathrm{OH}$ modes in the Si plane, respectively. ${ }^{3}$

A band at $2109 \mathrm{~cm}^{-1}$ associated with $\mathrm{Si}-\mathrm{H}$ mode can be clearly found, it has Si-O-Si bridges grafted in the $\mathrm{Si}_{6}$ ring and $-\mathrm{OH}$ functional groups on the surface, which indicate a Kautsky-type structure. ${ }^{45}$ As mentioned above, the $\mathrm{Si}-\mathrm{H}$ mode in siloxene indicates that the edges or other surfaces of the $\mathrm{Si}_{6}$ rings are saturated with $\mathrm{H}$ atoms.

The $-\mathrm{OH}$ group, with a hydrogen bond, has broad band between $3200-3400 \mathrm{~cm}^{-1}$, indicating the oxidation and hydroxylation during the exfoliation process of siloxene from $\mathrm{CaSi}_{2}$.

This result indicates that most of the surface in the siloxene has been oxidized and hydroxylated.

In the infrared spectrum of germanane (Fig. S5-e in SI), the band centered at 1997 $\mathrm{cm}^{-1}$ (Ge-H stretch) and $640 \mathrm{~cm}^{-1}$ (Ge-H swing) show the existence of Ge-H vibration, where the direction of $-\mathrm{H}$ is parallel to the c-axis. The Ge-O-Ge stretching mode can be found at $824 \mathrm{~cm}^{-1}$, indicating that some parts of the plane have been oxidized or the glassy/amorphous oxide is present. Furthermore, no $-\mathrm{OH}$ vibration was found in germanane, suggesting that Ge preferentially bonds to $-\mathrm{H}$. 

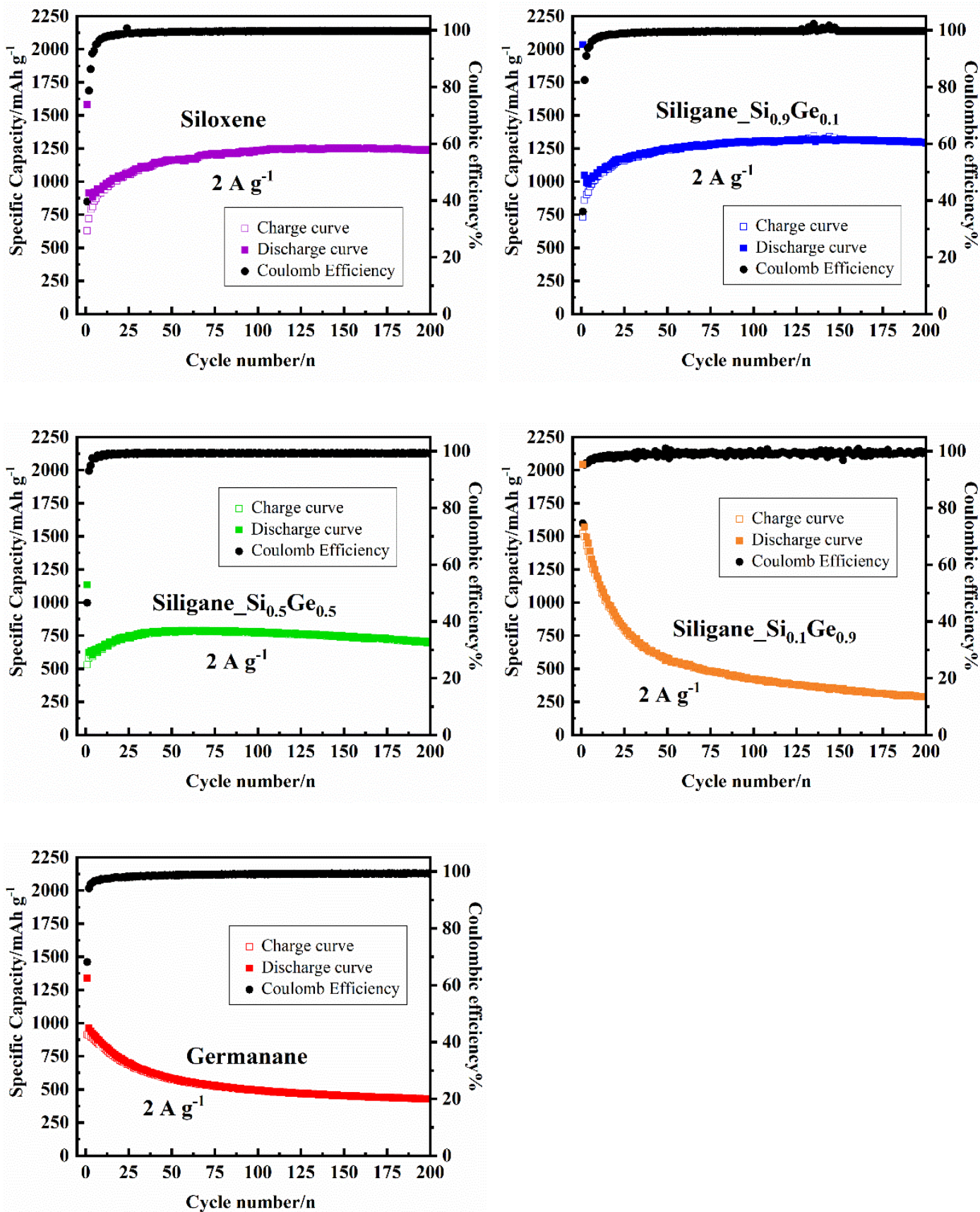

Fig. S6. The cycling performance and coulombic efficiency of siloxene, siligane_Si $\mathrm{i}_{0.9} \mathrm{Ge}_{0.1}$, siligane_Si $\mathrm{S}_{0.5} \mathrm{Ge}_{0.5}$, siligane_Si $\mathrm{S}_{0.1} \mathrm{Ge}_{0.9}$ and germanane at a current density of $2 \mathrm{~A} \mathrm{~g}^{-1}$ between $0.001-2.0 \mathrm{~V}$. 


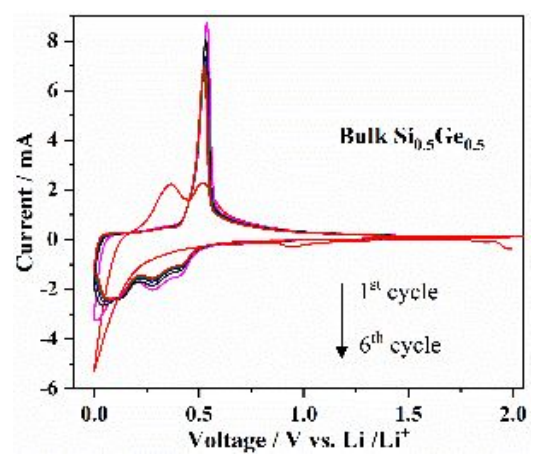

Fig.S7. The cyclic voltammograms curves of bulk $\mathrm{Si}_{0.5} \mathrm{Ge}_{0.5}$ at a scan rate of $0.1 \mathrm{mV} \mathrm{s}^{-1}$.

\section{References}

(1) Loaiza, L. C.; Monconduit, L.; Seznec, V. Siloxene: A Potential Layered Silicon Intercalation Anode for Na, Li and K Ion Batteries. J. Power Sources 2019, 417 (February), 99-107. https://doi.org/10.1016/j.jpowsour.2019.02.030.

(2) Loaiza, L. C.; Monconduit, L.; Seznec, V. Towards Germanium Layered Materials as Superior Negative Electrodes for Li- , Na- , and K-Ion Batteries. 2020, 1-11. https://doi.org/10.1002/batt.201900198.

(3) Xu, K.; Ben, L.; Li, H.; Huang, X. Silicon-Based Nanosheets Synthesized by a Topochemical Reaction for Use as Anodes for Lithium Ion Batteries. Nano Res. 2015, 8 (8), 2654-2662.

https://doi.org/10.1007/s12274-015-0772-4.

(4) Krishnamoorthy, K.; Pazhamalai, P.; Kim, S.-J. Two-Dimensional Siloxene Nanosheets: Novel HighPerformance Supercapacitor Electrode Materials. Energy Environ. Sci. 2018, 11 (6), 1595-1602. https://doi.org/10.1039/C8EE00160J.

(5) Yamanaka, S.; Matsu-ura, H.; Ishikawa, M. New Deintercalation Reaction of Calcium from Calcium Disilicide. Synthesis of Layered Polysilane. Mater. Res. Bull. 1996, 31 (3), 307-316.

https://doi.org/https://doi.org/10.1016/0025-5408(95)00195-6. 